\title{
Pemanfaatan Teknologi Augmented Reality untuk Memilih Model Kacamata di Central Optikal 165 dengan Menggunakan Metode Markerless Berbasis Android
}

\author{
Tarmin Abdulghani ${ }^{1}$, Radityatama Mulia Sembada ${ }^{2}$ \\ Program Studi Teknik Informatika \\ Universitas Suryakancana \\ tarmin@artagani.com ${ }^{I}$,jindandajun104@gmail.com²
}

\begin{abstract}
Implementation Technology Augmented Reality For Choosing Model Glasses In Central Optikal 165 With Using Markerless Method Android Based is an application android based. This application is made to make easier and attractive user when user doing selecting glasses, then application is opened front facing camera to detecting user's face and showing 3D model object glasses.

Application Design Application of Augmented Reality Technology Using Markerless Method based on Android UML (Unidentified Modeling Language) paradigm concept to describe the making of Augmented Reality application for the selection of Glasses Model.
\end{abstract}

Keywords: android,augmented reality, glasses, unity.

Penerapan Teknologi Augmented Reality Kacamata Dengan Menggunakan Metode Markerless Berbasis Android adalah sebuah aplikasi yang dibangun berbasis android. Aplikasi ini dibuat untuk mempermudah sekaligus hal yang menarik dalam melakukan pemilihan kacamata yang dapat dilakukan dengan cara membuka kamera depan, kemudian aplikasi mendeteksi wajah dan memunculkan model objek 3D kacamata terhadap wajah calon pembeli.

Perancangan aplikasi Penerapan Teknologi Augmented Reality Kacamata mempergunakan Metode Markerless berbasis Android menggunakan konsep paradigma UML (Unidentified Modeling Languange) untuk menggambarkan pembuatan aplikasi Augmented Reality untuk pemilihan Model Kacamata.

Kata kunci : android,augmented reality, kacamata, unity.

\section{PENDAHULUAN}

\subsection{Latar Belakang Masalah}

Perkembangan zaman teknologi yang semakin hari semakin canggih dan modern telah mengubah pola hidup manusia menjadi dinamis, dimana manusia berupaya menemukan inovasi-inovasi untuk memenuhi kebutuhan hidupnya. Hal itu lah yang menyembabkan terciptanya teknologi. Teknologi tentunya dibuat untuk mempermudah pekerjaan manusia dalam menghasilkan sesuatu. Pemanfaatan teknologi tidak hanya terbatas pada bidang pendidikan namun juga pada bidang komunikasi, bidang transportasi, dan bidang bisnis. Tetapi juga menyangkut masalah umum, misalnya pelayanan dalam bisnis, sosial atau pun kebutuhan yang lainnya, dimana manusia tersebut kebutuhannya akan terpenuhi.

Dalam hal ini tentunya teknologi akan berubah kedudukan kebutuhannya yang dulunya kebutuhan sekunder menjadi kebutuhan primer. Hampir semua orang memanfaatkan teknologi dengan cara komputerisasi sebagai alat bantu dalam kegiatan.

Central Optikal 165 merupakan sebuah toko optik yang berlokasi di Jl. Siti Jenab No 67 Cimaya samping Bank BJB Cianjur menjual kacamata, frame, lensa dan aksesoris kacamata. Pasien juga bisa diperiksa mata langsung dan menerima resep dari dokter. Di Central Optikal 165 saat ini menggunakan katalog berbentuk kertas sebagai mediasi pengenalan produk, dan menawarkan barang sesuai dengan yang tersedia di toko. Dengan teknologi AR, ketika calon pembeli ingin memesan kacamata yang stok terjual habis/tidak tersedia dalam katalog. Kini calon pembeli dapat melihat seperti apa bentuk, warna frame, warna lensa dari kacamata (berbentuk objek 3D) didalam layar smartphone. Dengan pemanfaatan AR ini dapat memudahkan calon pembeli dalam pemilihan kacamata.

\subsection{Rumusan Masalah}

Berdasarkan latar belakang, maka rumusan masalah dari hasil penelitian ini adalah bagaimana cara Pemanfaatan Teknologi Augmented Reality Pada Sistem Aplikasi Kacamata.

\subsection{Maksud dan Tujuan}

Maksud dari penilitian tugas akhir ini adalah bagaimana cara Pemanfaatan Teknologi Augmented Reality Kacamata Pada Aplikasi Pemesanan Kacamata Berbasis Android. 
Tujuan penelitian dari tugas akhir ini adalah :

a. Memanfaatkan teknologi Augmented Reality pada aplikasi kacamata.

b. Membantu calon pembeli dalam memilih kacamata.

\subsection{Batasan Masalah}

Permasalahan yang akan di bahas pada penelitian tugas akhir ini yaitu:

1. Memberikan gambaran kacamata berupa objek 3D terhadap calon pembeli.

2. Augmented Reality menggunakan metode markerless.

3. Aplikasi digunakan untuk calon pembeli dalam memilih kacamata.

\section{METODE}

\subsection{Tempat Penelitian}

Central Optikal 165 merupakan suatu toko optik yang berdiri sejak tahun 2010 yang bertempatkan di Jalan Siti Jenab No. 67 samping Bank BJB Cimaya,Cianjur. Di tahun 2013 membuka cabang tahun 2013 bertempatkan di Jalan Raya Ciranjang No.16 (Depan praktek dr. Slamet) Ciranjang- Cianjur.

Pelopor dan pendiri Central Optikal 165 ini adalah Bapak Ade Iwan Ridwansyah.

\subsection{Pengertian Kacamata}

Menurut KBBI kacamata adalah lensa tipis untuk mata guna menormalkan dan mempertajam penglihatan (ada yang berangka dan ada yang tidak).

Menurut [1] kacamata merupakan sebuah alat bantu penglihatan bagi seseorang yang memiliki gangguan pada indera penglihatan.

\subsection{Pengertian Frame}

Frame adalah bingkai dari kacamata terbuat dari bahan plastik. Fungsi dari frame kacamata adalah sebagai penopang lensa kacamata agar dapat digunakan.

Frame atau bingkai menurut KBBI adalah bilah (papan, rotan) yang dipasang di sekeliling suatu benda supaya kuat; simpai (roda); lis (pigura dsb); rangka (kacamata).

\subsection{Pengertian Lensa}

Lensa adalah sebuah alat untuk mengumpulkan atau menyebarkan cahaya, biasanya dibentuk dari sepotong gelas yang dibentuk. Konstruksi lensa yang paling umum adalah lensa speris (spherical lens), yaitu lensa dengan bidang antarmuka yang melengkung speris (spherical curvature), yaitu kelengkungan bidang permukaan bola dengan radius speris (radius of curvature) tertentu [1], [2].

Jenis-jenis lensa kacamata yang perlu diketahui agar sesuai kebutuhan. Menurut Tokopedia.

\subsubsection{Lensa Kacamata Single Vision}

Lensa jenis ini disebut juga sebagai lensa tunggal karena hanya terdiri dari satu titik fokus yang dapat memperbaiki gangguan penglihatan untuk satu ukuran saja. Lensa tunggal biasanya digunakan untuk beberapa pengguna dengan keluhan seperti rabun jauh (miopi) dengan lensa minus, dan rabun dekat (hipermetropi) dengan lensa positifnya, serta penglihatan berbayang (astigmatisma) dengan lensa silinder.

\subsubsection{Lensa Kacamata Bifocal}

lensa ini memiliki dua titik fokus yang dapat membantu penglihatan dengan lensa jarak jauh di bagian atas dan lensa jarak dekat di bagian bawahnya. Lensa ini dikategorikan sebagai lensa yang cukup sering digunakan dan umumnya dapat ditemukan pada penderita usia 40 tahun ke atas dengan tingkat fokus lensa yang buruk (presbiopi) dikarenakan lanjut usia.

\subsubsection{Lensa Kacamata Transition}

Keunikan dari lensa jenis ini adalah kemampuannya untuk berubah warna. Perubahan warna pada lensa terjadi karena adanya sifat cahaya yang terpolarisasi. Maka dari itu, pengguna yang sedang berada di luar ruangan dan terpapar oleh sinar matahari akan membuat lensa kacamata menjadi gelap. Sebaliknya, pengguna yang berada dalam ruangan dengan pencahayaan yang minim tidak akan merubah warna lensa dan akan membuatnya tetap menjadi bening.

\subsubsection{Lensa Kacamata Progresif}

Seperti lensa bifokal, lensa progresif tidak jauh berbeda karena sama-sama memiliki titik fokus ganda yang berguna untuk mengoreksi rabun dekat dan rabun jauh. Keuntungan yang didapat dengan menggunakan lensa progresif adalah pengguna mampu untuk melihat dalam sudut pandang dengan jarak sedang. Akan tetapi, lensa progresif tidak memiliki garis pembatas seperti pada lensa bifokal.

\subsubsection{Lensa Kacamata Mirror}

Berbeda dengan jenis lensa sebelumnya yang tidak memiliki warna atau bening, lensa kacamata mirror adalah jenis lensa yang digunakan untuk kacamata hitam. Jenis lensa ini merupakan tren yang sedang diminati, karena menghadirkan nuansa yang lebih klasik jika dibandingkan dengan kacamata hitam kebanyakan. Hal ini bisa jadi karena lensa kacamata mirror menghadirkan siluet dengan berbagai warna cerah yang menarik, serta bentuk yang beragam sehingga pengguna dapat dengan bebas memilih model yang sesuai dengan keinginan.

\subsubsection{Lensa Kacamata Minus}

Seperti yang telah disebutkan sebelumnya, lensa kacamata minus adalah lensa yang digunakan untuk membantu penglihatan pengguna yang mengalami rabun jauh (miopi). Lensa minus berbentuk cekung dan cara kerjanya adalah dengan cara mengoreksi mata yang tidak terakomodasi ketika melihat dari jarak jauh. Titik fokus yang tadinya berada di depan retina dan bayangannya yang kabur diatur sedemikian rupa agar bayangan dapat tersebar dan jatuh tepat pada retina. Lensa kacamata minus lebih sering digunakan ketika melakukan aktivitas di luar ruangan seperti saat berkendara atau berangkat ke kantor dan sekolah. Pengguna yang menggunakan lensa minus dalam jarak dekat untuk jangka waktu lama, terutama untuk yang menggunakan gadget, akan mengalami mata perih dan lelah lebih cepat.

\subsubsection{Lensa Kacamata Plus}

Kebalikan dari lensa minus, lensa kacamata plus memiliki bentuk cembung. Lensa jenis ini juga memiliki fungsi yang berbeda dari lensa kacamata minus, seperti yang telah disebutkan sebelumnya. Pengguna dengan 
rabun dekat (hipermetropi) memiliki sistem lensa yang lemah sehingga bayangan yang dipantulkan jatuh di belakang retina. Lensa kacamata plus berguna untuk mengakomodasi mata pengguna dengan cara mengumpulkan cahaya dan memperbaiki titik fokus bayangan tersebut agar bisa jatuh tepat pada retina.

\subsubsection{Lensa Kacamata Silinder}

Lensa jenis silinder digunakan untuk membantu penglihatan pengguna dengan gangguan astigmatisma. Penderita dengan gangguan astigmatisma memiliki bentuk bola mata yang kurang melengkung dan mengaburkan titik fokus berkas cahaya yang masuk ke dalam mata. Toppers mungkin sering mendengar penderita astigmatisma yang tidak bisa membedakan garis mendatar (horizontal) dengan garis tegak lurus (vertikal) dalam waktu bersamaan karena bentuk kornea yang tidak bulat sepenuhnya. Lensa kacamata silinder akan membantu penderita untuk membiaskan cahaya dengan benar baik secara horizontal maupun vertikal agar tidak menjadi kabur.

\subsubsection{Lensa Kacamata Berubah Warna}

Lensa kacamata yang dapat berubah warna atau photochromic sebenarnya adalah lensa transisi. Lensa jenis ini memiliki kandungan photochromic yang telah dipatenkan sehingga mampu berubah warna sesuai dengan paparan cahaya atau sinar UV yang ada. Makin besar intensitas cahaya, makin gelap tingkat warna yang dihasilkan lensa. Sebaliknya, ketiadaan cahaya akan membuat lensa jenis ini menjadi jernih seperti biasanya. Lensa jenis photochromic sangat baik untuk memelihara kesehatan mata dalam jangka panjang.

2.4.10 Kacamata 5 Lensa

Mungkin beberapa dari kalian penasaran, apa sih sebenarnya kacamata 5 lensa itu? Secara sederhana, kacamata jenis ini adalah kacamata yang memiliki 5 lensa berbeda yang dapat digunakan sesuai kebutuhan. Maka dari itu, jangan kaget apabila melihat lensa kacamata yang dapat dilepas dan dipasang kembali. Kacamata 5 lensa dapat juga disebut sebagai kacamata clip-on.

\subsection{Pengertian Markerless Augmented Reality}

Menurut [2],[3] Augmented Reality memiliki tiga karakteristik yaitu :

1. Menggabungkan antara dunia nyata dan virtual.

2. Interaktif pada waktu nyata.

3. Tergolong dalam lingkungan 3-D Augmented Reality dapat diklasifikasikan menjadi dua berdasarkan ada tidaknya pengguaan marker yaitu :

1) Markerless Augmented Reality

Markerless Augmented Reality salah satu metode Augmented Reality yang saat ini sedang berkembang adalah metode Markerless Augmented Reality. Dengan metode ini pengguna tidak perlu lagi menggunakan sebuah marker untuk menampilkan objek 3D atau yang lainnya. Sekalipun dinamakan dengan markerless namun aplikasi tetap berjalan dengan melakukan pemindaian terhadap objek, namun ruang lingkup yang dipindai lebih luas dibanding dengan Marker Based Tracking. Seperti yang saat ini dikembangkan oleh perusahaan Augmented Reality terbesar di dunia Total Immersion.

Android merupakan OS (Sistem Operasi) Mobile yang tumbuh ditengah OS lainnya yang berkembang dewasa ini. OS lainnya seperti Windows Mobile, OS iPhone, Symbian, dan masih banyak lagi selain itu. Akan tetapi, OS yang ada ini menjalankannya dengan memprioritaskan aplikasi inti yang dibangun sendiri tanpa melihat dari potensi yang cukup besar dari aplikasi pihak ketiga (Hermawan, 2011). [4]

Oleh karena itu, ada keterbatasan dari aplikasi pihak ketiga untuk mendapatkan Data asli ponsel atau Smartphone, percakapan antar proses serta distribusidari aplikasi pihak ketiga untuk platform mereka.

Kacamata merupakansebuah alat bantu penglihatan bagi seseorang yang memiliki gangguan pada indera penglihatan. Semakin pesatnya perkembangan

teknologi khususnya benda-benda elektronik yang

menggunakanan layar monitor, setiap orang dituntut untuk mampu mengikuti perkembangan tersebut, seringnya melihat layar monitor, terkena paparan radiasi dari layar monitor baik komputer, telepon seluler, maupun

benda elektronik lainnya maka semakin lama akan berpengaruh terhadap daya penglihatan seseorang [1].[5]

Menurut [3] Pemesanan dalam arti umum adalah perjanjian pemesanan tempat antara 2 (dua) pihak atau lebih, perjanjian pemesanan tempat tersebut dapat berupa perjanjian atas pemesanan suatu ruangan, kamar, tempat

duduk dan lainnya, pada waktu tertentu dan disertai dengan produk jasanya.

Salah satu metode augmented reality saat ini sedang berkembang adalah metode Markerless Augmented Reality, dengan metode ini pengguna tidak perlu lagi menggunakan sebuah marker untuk menampilkan elemen - elemen digital. Seperti yang saat ini dikembangkan oleh perusahaan Augmented Reality terbesar di dunia Total Immersion dan Qualcomm, mereka telah membuat berbagai macam teknik MarkerlessTracking sebagai teknologi andalan mereka, seperti Face Tracking, 3D Object Tracking, dan Motion Tracking.[4], [6].

\subsection{Android Studio}

Android Studio adalah IDE (IntegratedDevelopment Environment) resmi untuk Jurnal Ilmiah Komputer dan Informatika pengembangan aplikasi Android dan bersifat open source atau gratis. Peluncuran Android Studio ini diumumkan oleh Google pada 16 mei 2013 pada event Google I/O Conference untuk tahun2013. Sejak saat itu, Android Studio mengantikan Eclipsesebagai IDE resmi untuk mengembangkan aplikasiAndroid, Android Studio sendiri dikembangkan berdasarkan IntelliJ IDEA yang mirip dengan Eclipse disertai dengan ADT plugin (Android Development Tools). Android Studio memiliki fitur Projek berbasispada Gradle Build, Refactory dan pembenahan bug yang cepat Tools baru yang bernama "Lint" dikalim dapat memonitor kecepatan, kegunaan, serta kompetibelitas aplikasi dengan cepat. Mendukung Proguard And App- signing untuk keamanan, Memiliki GUI aplikasi android lebih mudah, Didukung oleh Google Cloud Platfrom untuk setiap aplikasi yang dikembangkan [5] [7]. 


\subsection{Blender}

Menurut [6], [8] Blender merupakan paket aplikasi pemodelan dan animasi tiga dimensi yang memiliki berbagai fungsi yang tidak dimiliki aplikasi tiga dimensi lainnya. Blender juga semacam program yang dapat melakukan berbagai fungsi.

1. Blender adalah aplikasi pemodelan tiga dimensi yang dapat membuat sebuah karakter untuk film.

2. Blender memiliki sebuah alat yang kuat untuk pewarnaan permukaan model.

3. Blender memiliki sebuah fasilitas dalam rigging dan animasi yang sangat kuat. Model tiga dimensi yang dibuat dapat dirancang untuk bergerak dan beraksi sedemikian rupa.

4. Blender memiliki mesin rendering sendiri dan dapat dianggap layaknya studio pencahayaan yang lengkap untuk sebuah film.

5. Tidak seperti paket aplikasi 3D lainnya, Blender memiliki compositing module sendiri, sehingga hasil live shoot bisa langsung di masukkan dan diintegrasikan dengan model tiga dimensi. Blender juga memiliki editor pengurutan video yang unik, sehingga memungkinkan untuk memotong dan mengedit video tanpa harus bergantung pada aplikasi pihak ketiga tambahan untuk tahap editing akhir produksi.

6. Selain semua itu, Blender juga memiliki fasilitas Game Engine.

\subsection{UML (Unified Modeling Languange)}

Menurut [7],[9] Unified Modeling Language (UML) adalah bahasa spesifikasi standar yang dipergunakan untuk mendokumentasikan, menspesifikasikan dan membangun perangkat lunak. UML merupakan metodologi dalam mengembangkan sistem berorientasi objek dan juga merupakan alat untuk mendukung pengembangan sistem.

UML adalah alat komunikasi yang konsisten dalam mendukung para pengembang sistem saat ini [8]. Dari beberapa pengertian di atas dapat diambil kesimpulan Use case diagram merupakan pemodelan untuk menggambarkan fungsionalitas yang diharapkan dari sebuah sistem.

\section{a. Usecase Diagram}

Usecase diagram merupakan pemodelan untuk kelakuan sistem informasi yang akan dibuat. Use case bekerja dengan mendeskripsikan tipikal interaksi antara user sebuah sistem dengan sistemnnya sendiri melalui sebuah cerita bagaimana sistem itu dipakai.

b. Swimlane Diagram

Swimlane diagram merupakan diagram yang menggambarkkan workflow atau aktivitas dari sebuah sistem yang ada pada perangkat lunak.

\subsection{Visual Paradigm}

Visual Paradigm merupakan aplikasi untuk merancang sebuah aplikasi atau biasa disebut aplikasi rekayasa perangkat lunak. Dengan Visual Paradigm sebuah aplikasi dapat digambarkan dalam sebuah rancangan aplikasi dapat digambarkan dalam sebuah rancangan simbol dan gambar tanpa koding yang menjelaskan bagaimana aplikasi tersebut akan berjalan setelah selesai nantinnya. Visual Paradigm adalah salah satu alat bantu Unified Modeling Language (UML) yang digunakan untuk membuat Use Case Diagram, Activity Diagram , Class Diagram, dan Sequence Diagram [9], [10]

\subsection{Flowchart}

Flowchart adalah penggambaran secara grafik dari langkah-langkah dan urut-urutan prosedur dari suatu program. Flowchart menolong analis dalam memecahkan masalah kedalam segmen-segmen yang lebih kecil dan menolong dalam menganalisis alternatif-alternatif lain dalam pengoperasian. Flowchart biasanya mempermudah penyelesaian suatu masalah khususnya masalah yang perlu dipelajari dan dievaluasi lebih lanjut. Proses di lingkungan organisasi pada umumnya merupakan suatu rangkaian kegiatan yang berulang. Setiap siklus kegiatan tersebut biasanya dapat dipecahkan ke dalam beberapa langkah kecil. Dari uraian langkah-langkah tersebut, kita dapat mencari langkah mana saja yang bisa kita perbaiki.[10], [11].

\subsection{Storyboard}

Storyboard adalah area berseri dari sebuah gambar sketsa yang digunakan sebagai alat perencanaan untuk menunjukkan secara visual bagaimana aksi dari sebuah cerita berlangsung. Storyboard merupakan naskah yang dituangkan dalam bentuk gambar atau sketsa yang berguna untuk lebih memudahkan cameraman dalam pengambilan gambar. Storyboard secara harfiah berarti dasar cerita, storyboard adalah penjelasan bagaimana cara seseorang akan membuat suatu proyek. Jika diumpamakan sebagai pembuatan film, maka bisa dibilang bahwa storyboard adalah skenario film tersebut [11],[12].

\section{III.HASIL PENELITIAN}

\subsection{Analisis Kebutuhan Fungsional}

Kebutuhan fungsional menjelaskan mengenai proses - proses apa saja yang akan dilakukan oleh sistem deskripsi dan kebutuhan aktivitas - aktivitas dari layanan yang harus disediakan oleh sistem. Kebutuhan fungsional user merupakan pernyataan level tinggi dari apa saja yang seharusnya dilakukan sistem tetapi kebutuhan sistem menggambarkan layanan sistem secara detail. Berikut adalah fungsi atau yang dibutuhkan oleh sistem yang nantinya akan digunakan oleh pengguna.

Berikut kebutuhan fungsional yang dibutuhkan sistem : 1. Sistem akan menampilkan objek 3D kacamata.

2. Setelah penggunakan melakukan login dan ketika memilih kacamata, dan memilih tombol "Coba AR" maka sistem akan menuju ke AR kamera dan menampilkan menu kacamata. Ada dua kategori dari menu tersebut yaitu, kategori kacamata gaya dan kategori kacamata baca. Kemudian sistem akan menampilkan AR kamera berupa objek 3D Kacamata.

3. Objek 3D di visualisasikan melalui kamera smartphone 


\subsection{Analisis Kebutuhan Non Fungsional}

Analisis kebutuhan non fungsional menggambarkan kebutuhan perangkat keras, perangkat lunak, GUI (Graphic User Interface) dan analisis pengguna. Berikut adalah kebutuhan non fungsional yang dibutuhkan oleh sistem :

1. Perangkat Keras

Pengkat Keras yang digunakan adalah teknologi augmented reality, yang merupakan perangkat smarthphone android dengan spesifikasi minimal yang dibutuhkan sebagai berikut : Tabel 1 Perangkat Keras

\begin{tabular}{|c|l|l|}
\hline No & Hardware & Spesifikasi \\
\hline 1 & Layar & 4-6 Inch \\
\hline 2 & RAM & $2 \mathrm{~GB}$ \\
\hline 3 & Memori Internal & $4 \mathrm{~GB}-8 \mathrm{~GB}$ \\
\hline 4 & Kamera & $5 \mathrm{Megapixel}$ \\
\hline 5 & Internet & $\begin{array}{l}\text { Kecepetan internet } \\
100 \mathrm{~kb} / \mathrm{s}-1 \mathrm{MB} / \mathrm{s}\end{array}$ \\
\hline
\end{tabular}

2. Perangkat Lunak

Perangkat lunak yang digunakan untuk sistem pemesanan kacamata menggunakan teknologi augmented reality adalah minimal OS android versi 4.4 ke atas.

3. GUI (Graphic User Interface)

a) Warna

Pemilihan warna untuk pembuatan aplikasi pada umumnya menggunakan warna yang tidak terlalu mencolok dan sewajarnya. Hal ini dikarenakan karena mayoritas pengguna bukan untuk anak - anak.

b) Font

Ukuran dan jenis font yang digunakan dalam pembuatan aplikasi akan menggunakan font yang umum digunakan. Font tidak terlalu kecil atau terlalu besar dan jenis hurufnya akan menggunakan times new roman atau arial untuk huruf dalam aplikasi.

\subsection{Usecase Diagram}

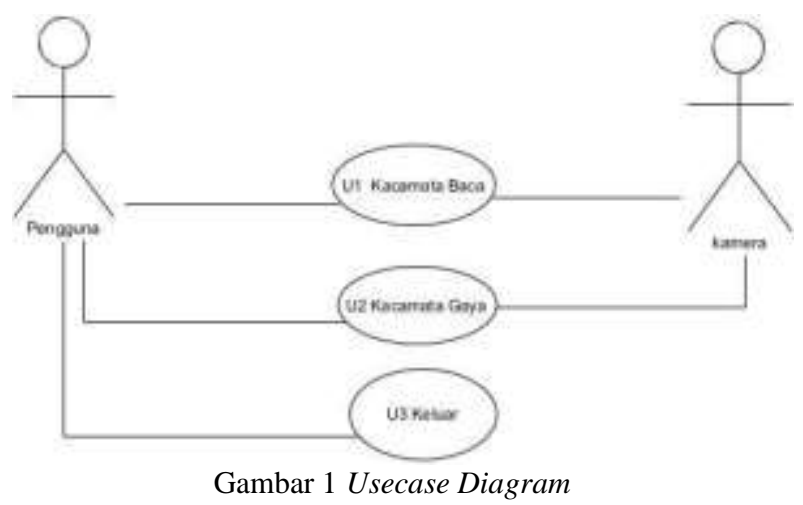

Berdasarkan Gambar 1 Usecase Scenario terdapat dua Usecase, yaitu U1 Kacamata Baca dan U2 Kacamata Gaya. Kedua usecase ini berfungsi untuk bisa mengakses Kamera AR Kacamata Baca/Gaya dan dua aktor yaitu pengguna untuk menjalankan aplikasi dan aktor kamera untuk memindai wajah pengguna (Face Tracking).

\subsection{Swimlane Diagram}

1. Swimlane Diagram Halaman Utama

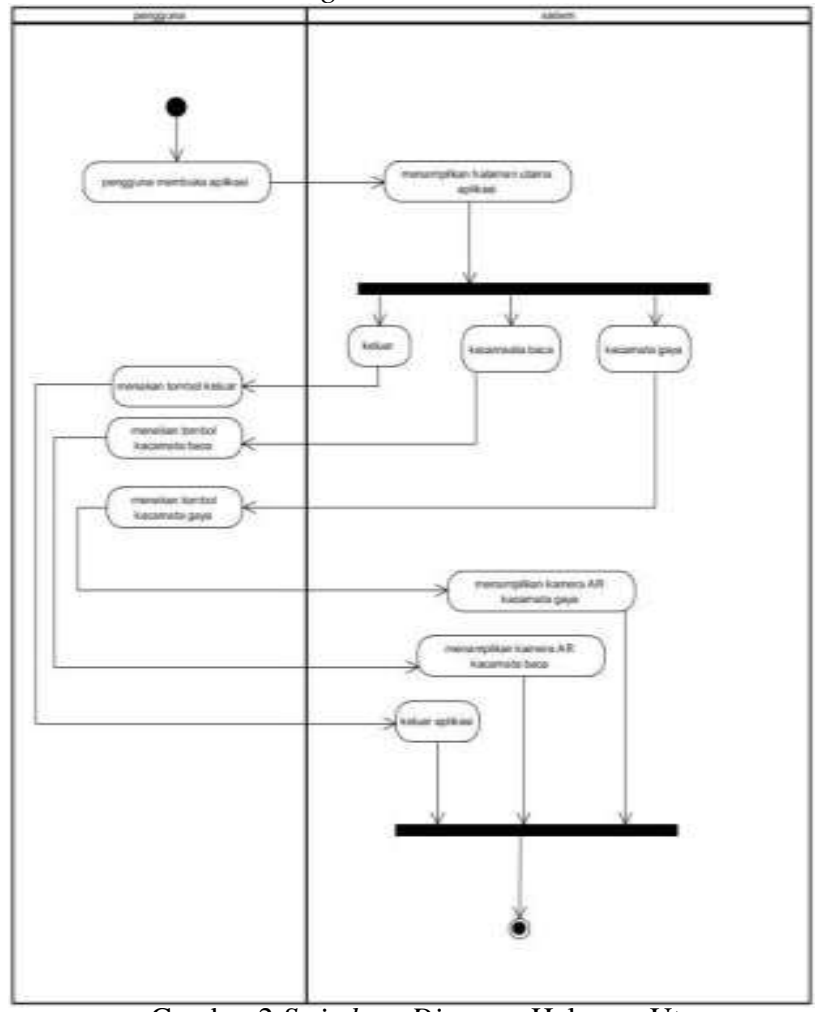

Gambar 2 Swimlane Diagram Halaman Utama

Berdasarkan Gambar 3.2. Swimlane Diagram Halaman utama merupakan swimlane diagram untuk alur halaman paling awal. Aktor yaitu pengguna masuk kedalam sistem, kemudian sistem menampilkan halaman utama.

2. Swimlane Diagram Kamera AR Kacamata Baca/Gaya 


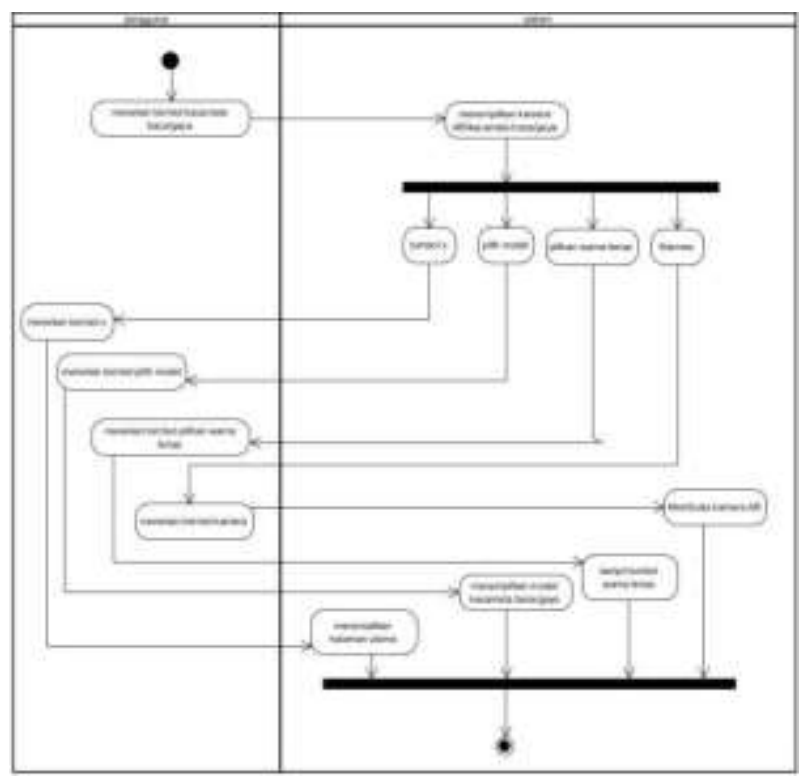

\subsection{Flowchart}

Dibawah ini merupakan flowchart dari sistem keseluruhan :

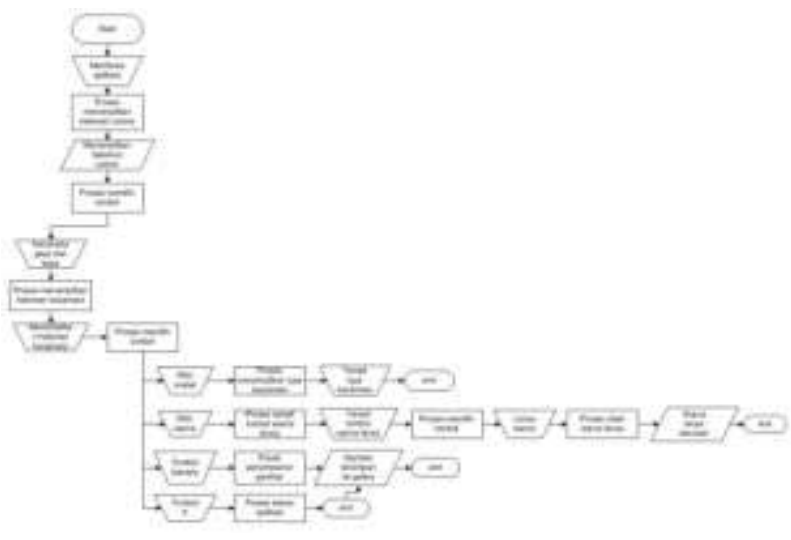

Gambar 4 Flowchart

\subsection{Storyboard}

Tabel 2 StoryBoard

\begin{tabular}{|l|l|l|}
\hline No. & Visual & Penjelasan \\
\hline 1 & $\begin{array}{l}\text { Tombol keluar : untuk } \\
\text { keluar dari aplikasi. } \\
\text { Tombol kacamata baca } \\
: \text { membuka AR kamera } \\
\text { kacamata baca. } \\
\text { Tombol kacamata gaya : } \\
\text { membuka AR kamera } \\
\text { kacamata gaya. } \\
\end{array}$ & $\begin{array}{l}\text { Tatar Belakang } \\
\text { Background Kacamata. }\end{array}$ \\
\hline 2 & $\begin{array}{l}\text { Tombol kembali : untuk } \\
\text { kembali ke halaman } \\
\text { utama. } \\
\text { Tombol Pilihan Warna : } \\
\text { untuk menampilkan } \\
\text { daftar varian warna. }\end{array}$ \\
\hline
\end{tabular}

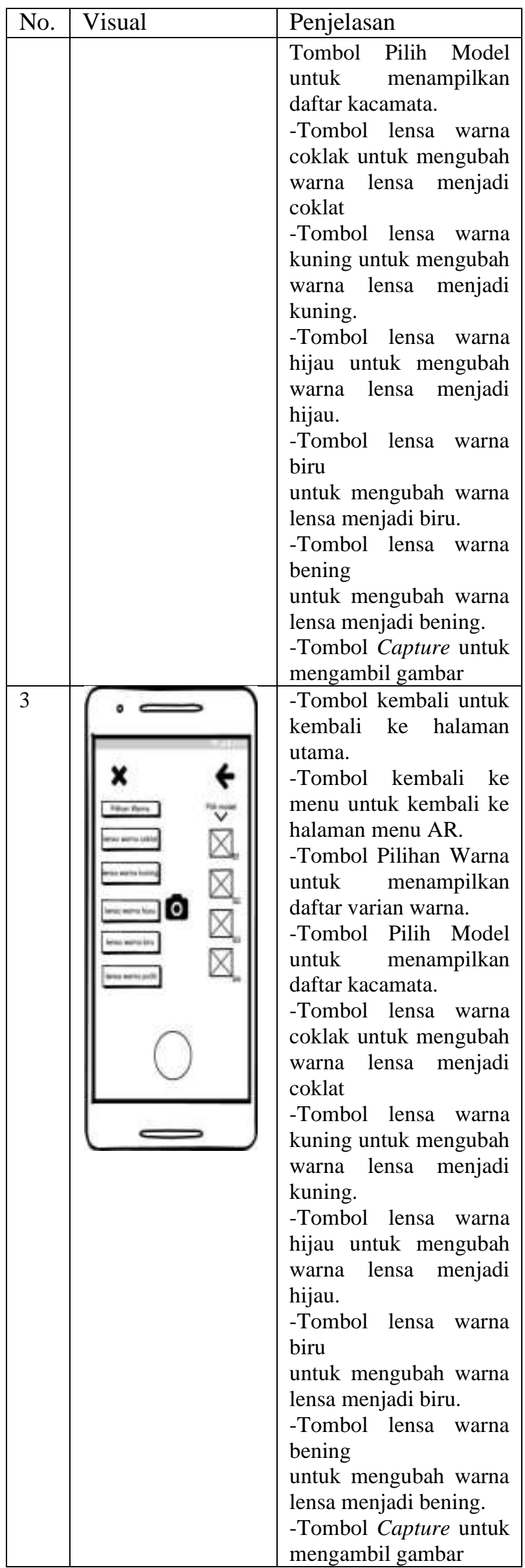




\subsection{Analisis Kebutuhan Marker}

Tabel 3 Analisis Kebutuhan Marker

\begin{tabular}{|c|c|c|c|c|}
\hline No & $\begin{array}{l}\text { Nama } \\
\text { Marker }\end{array}$ & Simbol & $\begin{array}{l}\text { Jarak } \\
\text { Min }\end{array}$ & $\begin{array}{l}\text { Jarak } \\
\text { Maks }\end{array}$ \\
\hline 1 & $\begin{array}{l}\text { Kacamata } \\
\text { Tipe A1 }\end{array}$ & 응 & $10 \mathrm{~cm}$ & $300 \mathrm{~cm}$ \\
\hline 2 & $\begin{array}{l}\text { Kacamata } \\
\text { Tipe A2 }\end{array}$ & 00 & $10 \mathrm{~cm}$ & $300 \mathrm{~cm}$ \\
\hline 3 & $\begin{array}{l}\text { Kacamata } \\
\text { Tipe A3 }\end{array}$ & xit? & $10 \mathrm{~cm}$ & $300 \mathrm{~cm}$ \\
\hline 4 & $\begin{array}{l}\text { Kacamata } \\
\text { Tipe A4 }\end{array}$ & $\triangle O$ & $10 \mathrm{~cm}$ & $300 \mathrm{~cm}$ \\
\hline 5 & $\begin{array}{l}\text { Kacamata } \\
\text { Tipe B1 }\end{array}$ & vere & $10 \mathrm{~cm}$ & $300 \mathrm{~cm}$ \\
\hline 6 & $\begin{array}{l}\text { Kacamata } \\
\text { Tipe B2 }\end{array}$ & & $10 \mathrm{~cm}$ & $300 \mathrm{~cm}$ \\
\hline 7 & $\begin{array}{l}\text { Kacamata } \\
\text { Tipe B3 }\end{array}$ & & $10 \mathrm{~cm}$ & 300 \\
\hline
\end{tabular}

\section{IV.PEMBAHASAN}

\subsection{Implementasi Perangkat Keras}

Dibutuhkan spesifikasi khusus dalam kebutuhan perangkat keras untuk mengimplementasikan Pemanfaatan Teknologi Augmented Reality Untuk Memilih Model Kacamata Di Central Optikal 165 Dengan Menggunakan Metode Markerless Berbasis Android ini yaitu:

Processor : Intel Core i5 2320

Harddisk : $1 \mathrm{~GB}$

Memory $\quad: 8 \mathrm{~GB}$

Monitor / LCD Laptop

\subsection{Implementasi Perangkat Lunak}

Berikut spesifikasi perangkat lunak yang digunakan dalam tahap pembuatan teknologi Augmented Reality Pemanfaatan Teknologi Augmented Reality Untuk Memilih Model Kacamata Di Central Optikal 165 Dengan Menggunakan Metode Markerless Berbasis Android adalah sebagai berikut :

a. Sistem operasi android.

b. Minimal android versi 7.0+ (Nougat) ke atas.

4.3. Implementasi Antar Muka

1. Halaman Antar Muka

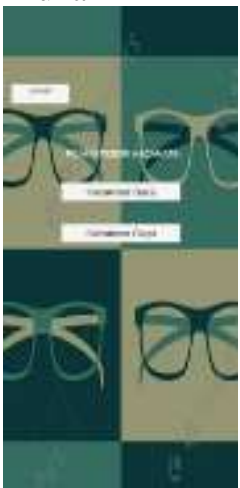

Gambar 5 Halaman Antar Muka
Berdasarkan Gambar 5 Antar Muka Halaman Menu Utama menampilkan Halaman Menu Utama yang terdiri dari 3 tombol fungsi, Tombol Keluar, Tombol Kacamata Baca, dan Tombol Kacamata Gaya.

2. Antar Muka Halaman Kamera AR Kacamata Gaya/Baca

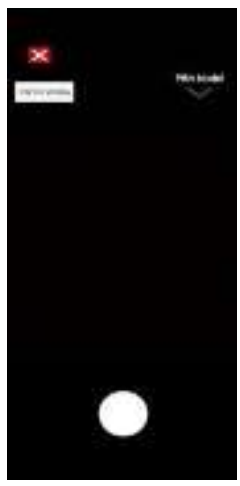

Gambar 6 Antar Muka Halaman Kamera AR Kacamata Gaya/Baca

Berdasarkan Gambar 6 Antar Muka Halaman Kamera AR Kacamata Baca/Gaya menampilkan Tombol Keluar, Tombol Pilihan Warna, Tombol Pilih Model, dan Tombol Capture.

3. Antar Muka Halaman Kamera AR Kacamata Gaya/Baca

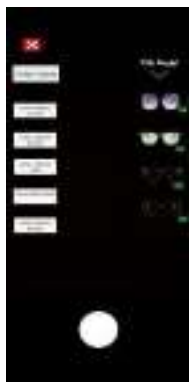

Gambar 7 Antar Muka Halaman Kamera AR Kacamata Gaya/Baca

Berdasarkan Gambar 7 Antar Muka Halaman Kamera AR Kacamata Baca/Gaya ketika tombol Pilih Model ditekan muncul tombol berupa format gambar PNG yaitu Tombol Kacamata Tipe A1, Tombol Kacamata Tipe A2, Tombol Kacamata Tipe A3, dan Tombol Kacamata Tipe A4. Kemudian ketika menekan Tombol Pilihan Warna maka muncul beberapa tombol yaitu, Tombol Lensa Warna Coklat, Tombol Lensa Warna Kuning, Tombol Lensa Warna Hijau, Tombol Lensa Warna Biru dan Tombol Lensa Warna Bening.

4. Antar Muka Halaman Kamera AR Kacamata Gaya/Baca

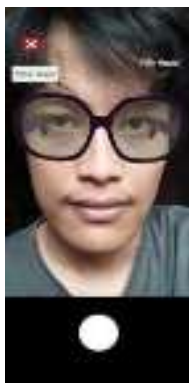

Gambar 8 Antar Muka Halaman Kamera AR 
Berdasarkan Gambar 8 Antar Muka Halaman KameraAR Kacamata Baca/Gaya menampilkan objek 3D ketika sudah menekan Tombol Kacamata Tipe A1 maka secara otomatis muncul ketika mendeteksi wajah (Facemesh).

5. Antar Muka Halaman Kamera AR Kacamata Gaya/Baca

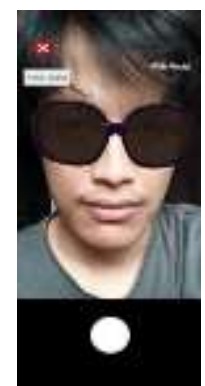

Gambar 9 Antar Muka Halaman Kamera AR Kacamata Gaya/Baca

Berdasarkan Gambar 9 Antar Muka Halaman Kamera AR Kacamata Baca/Gaya menampilkan perubahan warna lensa ketika Tombol Warna Coklat ditekan.

6. Antar Muka Halaman Kamera AR Kacamata Gaya/Baca

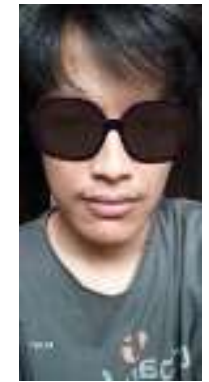

Gambar 10 Antar Muka Halaman Kamera AR Kacamata Gaya/Baca

Berdasarkan Gambar 10 Antar Muka Halaman Kamera AR Kacamata Baca/Gaya menampilkan gambar setelah Tombol Capture ditekan. Dan terdapat teks warna putih (watermark) untuk menandakan bahwa model kacamata yang telah dipilih.

7. Antar Muka Halaman Kamera AR Kacamata Gaya/Baca

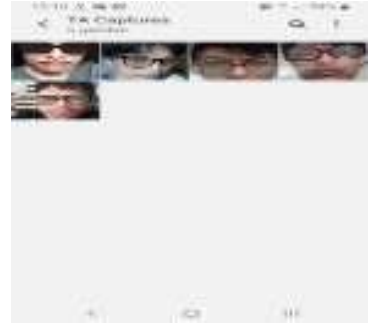

Gambar 11 Antar Muka Halaman Kamera AR Kacamata Gaya/Baca

Berdasarkan Gambar 11 Antar Muka Halaman Kamera AR Kacamata Baca/Gaya setelah Tombol Capture ditekan, maka secara otomatis sistem membuat album.

\section{V.KESIMPULAN}

5.1. Kesimpulan

Berdasar analisis selama melaksakan penelitian Tugas Akhir ini, dapat disimpulkan bahwa :
1. Telah dibuatnya aplikasi Augmented Reality (AR) menggunankan metode markerless sebagai Pemanfaatan Teknologi Augmented Reality yang dapat membantu calon pembeli dalam memilih kacamata.

2. Aplikasi dibuat dapat menampilkan objek 3D kacamata baca/gaya.

5.2. Saran

Dari hasil uji coba aplikasi secara langsung, aplikasi ini bisa dikembang dalam beberpa fitur di kacamata virtual AR, diantaranya :

1. Penambahan fitur preview gambar yang terdapat ketika pengguna telah melakukan capture gambar, kemudian pengguna dapat membuka gambar yang telah dibuat di album galeri.

2. Pengembangan dan penambahan Kacamata Baca/Gaya apabila nantinya terdapat beberapa kacamata yang baru.

3. Pengembangan pada perangkat lain seperti iOS, Windows.

4. Publikasi aplikasi ke dalam Google PlayStore.

\section{VI.REFERENSI}

[1] Novida, E., \& Sunandar, H. (2018). Sistem Pendukung Keputusan Pemilihan Produk Lensa Kacamata Menggunakan Metode Promethee Ii. Jurnal Pelita Informatika, 17(1), 71-78.

[2] Novida, E., \& Sunandar, H. (2018). Sistem Pendukung Keputusan Pemilihan Produk Lensa Kacamata Menggunakan Metode Promethee Ii. Jurnal Pelita Informatika, 17(1), 71-78.

[3] Azuma, R. T. (1997). A survey of augmented reality. Presence: Teleoperators and Virtual Environments, 6(4), 355-385. https://doi.org/10.1162/pres.1997.6.4.355

[4] Hermawan S, Stephanus. 2011."Mudah Membuat Aplikasi Android”.YYogyakarta : Andi Offset.

[5] Novida, E., \& Sunandar, H. (2018). Sistem Pendukung Keputusan Pemilihan Produk Lensa Kacamata Menggunakan Metode Promethee Ii. Jurnal Pelita Informatika, 17(1), 71-78.

[6] Muntahanah, Toyib, R., \& Ansyori, M. (2014). Penerapan Teknologi Augmented Reality Pada Aplikasi Katalog Rumah Berbasis Android. Prosiding SNATIF Ke-1, 4(1), 267-274. https://doi.org/10.1017/CBO9781107415324.0 04

[7] Andi, J. (2015). Pembangunan Aplikasi Child Tracker Berbasis Assisted - Global Positioning System ( A-GPS ) Dengan Platform Android. Jurnal Ilmiah Komputer Dan Informatika (KOMPUTA), 1(1), 1-8

[8] .Flavell, L. (2010). Modeling, Animation,

[9] Windu dan Grace. (2013). Sukses Membangun Aplikasi Penjualan dengan Java. Jakarta: PT. Elex Media Komputindo.

[10] Jurnal Ilmu Komputer Dan Informatika, 3(1), 
http://jurnal.uinsu.ac.id/index.php/algoritma/ar ticle/download/3148/1871

[11] Pressman, R. S. (2010). Software Engineering: A Practitioner's Approach. 7th Edition. New York : McGraw-Hill. 9(1), 28-36.

[12] Ridlo, I. A. (2017). Panduan pembuatan flowchart. Fakultas Kesehatan Masyarakat, 11(1), 1-27.
[13] Nurhasanah, Y. I., \& Senyelda, D. (2016). Implementasi Model CMIFED Pada Multimedia Interaktif Untuk Pembelajaran Anak Usia TK Dan Playgroup. Jurnal Informatika, Vol. 2(2), 12 